\title{
Representações de feminino e masculino em pesquisa com crianças
}

\begin{abstract}
Resumo: O trabalho apresenta os resultados de uma pesquisa cujo objetivo foi compreender quais representações de feminilidade e masculinidade as crianças constroem desde bem pequenas. O estudo inscreve-se na perspectiva teóricometodológica da pesquisa com crianças, que as entende como sujeitos e co-autoras. O referencial teórico incluiu os estudos da sociologia da infância, mais precisamente, os conceitos de cultura de pares e representação interpretativa, e os estudos sobre gênero. Dialogou-se com um grupo de crianças na faixa etária entre 4 e 5 anos, em suas culturas de pares, que frequentavam uma escola de Educação Infantil pública. Os resultados da pesquisa contribuíram para o entendimento de que, embora as crianças muitas vezes expressem compreensões - neste caso, sobre gênero - atreladas a uma visão adultocêntrica, os significados que acabam compartilhando e reproduzindo colaboram para a constituição de suas próprias identidades. E quando, no contexto de suas culturas de pares, alguns destes significados são tensionados, negociados, apreendidos e confrontados entre elas, acabam por produzir suas próprias culturas.
\end{abstract}

Palavras-chaves: Pesquisa com Crianças; Infância e Gênero; Educação Infantil; Cultura de Pares.

\section{Female and male representation in a research with children}

Abstract: The paper presents the results of a survey that aimed to understand which representations of femininity and masculinity children build since they are very young. The study is part of the theoretical and methodological perspective of research with children that understands them as subjects and co-authors. The theoretical framework included the sociology of childhood studies, more precisely, the peer culture concepts and interpretive representation, and studies on gender. It was spoken with a group of children aged between 4 and 5 years, in their peer culture, attending a public elementary school. The results of the research contributed to the understanding that, although children often express understanding - in this case, gender - linked to an adultview, the meanings they share and mimic collaborate to form their own identities. And when, in the context of their peer culture, some of these meanings are tensioned, negotiated, retained and confronted, end up producing their own cultures.

Keywords: Research with Children; Childhood and Gender; Childhood Education; Peer Culture.

\footnotetext{
1 Mestranda em Educação, na área dos Estudos Culturais, pela Universidade Luterana do Brasil - ULBRA. Especialista em Docência na Educação Infantil pela Universidade Federal do Rio Grande do Sul - UFRGS. Licenciada em Pedagogia pela Universidade Luterana do Brasil - ULBRA. E-mail: nlutiane@gmail.com

2 Doutora em Ciências Humanas pela Universidade Federal do Rio Grande do Sul (Porto Alegre, RS, Brasil), professora na Universidade Luterana do Brasil (Canoas, RS, Brasil) e na Universidade Federal do Rio Grande do Sul (Porto Alegre, RS, Brasil). E-mail: vorrabercosta@gmail.com

${ }^{3}$ Doutora em Educação pela Universidade Federal do Rio Grande do Sul. Professora no curso de pedagogia (área de Educação Infantil) e no Programa de Pós-Graduação em Educação da Faculdade de Educação da UFRGS. É membro no Núcleo de Estudos de Infâncias (GEIN) e do Núcleo de Pesquisa em Educação, Mídia e Subjetividade (NEMES) e Bolsista de Produtividade em Pesquisa do CNPq. E-mail: famarcello@gmail.com
} 


\section{Introdução - sobre crianças como sujeitos de pesquisa}

$\mathrm{P}$

or muito tempo, as pesquisas e estudos acadêmicos realizados nas diferentes áreas do conhecimento relacionados de alguma forma às crianças, debruçavam-se sobre objetivos que tratavam de interesses sobre e/ou para as crianças. Já nas últimas décadas, alguns estudiosos começaram a trilhar novos caminhos no que se refere a pesquisas com crianças, de forma que as crianças passassem de meros objetos de pesquisa a co-autoras das mesmas.

Conforme estudos recentes, em especial os da área da Sociologia da Infância, a infância se tornou um foco importante das pesquisas. Estudiosos como Willian A. Corsaro, Maria Manuela M. Ferreira, Bianca S. Guizzo, Fernanda Müller, Márcia Buss-Simão, entre outros, têm se dedicado a realizar suas pesquisas com as crianças e nos apontam que as crianças contribuem de maneira ativa para a produção e mudança cultural, ou seja, a cultura não é somente internalizada pelas crianças, mas também é modificada pela inserção da criança em um determinado contexto e pelas interações que instaura. Segundo Corsaro (2009, p. 31-32), as crianças "apreendem criativamente informações do mundo adulto para produzir suas culturas próprias e singulares". Assim, as crianças vêm ganhando destaque em diferentes pesquisas, mesmo sendo em proporções ainda bastante pequenas.

Em uma breve busca bibliográfica na área da Educação, verificamos quão restritas são as produções existentes em que pesquisadores propõem-se a dialogar e ouvir interesses, desejos e opiniões das crianças. Outros pesquisadores chamam a atenção para aspectos relevantes no que se refere a pesquisas com crianças. Como exemplo, ressaltam a postura que o pesquisador/ouvinte deve adotar, a qual deve estar destituída de poder e da presunção de certas verdades que enquanto adultos carregam, para que, assim, os sujeitos da pesquisa sintam-se confortáveis para se expressarem. Outro aspecto extremamente importante, apontado por Gobbi (2002), refere-se ao cuidado para não enquadrar a produção das crianças em padrões inequívocos, uma vez que elas mudam de ponto de vista e frequentemente reformulam suas afirmações.

Como professoras e pesquisadoras, uma delas atuante há alguns anos na Educação Infantil, percebemos que as crianças têm muito a nos dizer e a manifestar acerca de suas visões sobre o mundo em que vivem e do qual todos nós - adultos/pesquisadores e crianças - fazemos parte. É a partir deste posicionamento, de colocar-nos como mediadoras entre as crianças pequenas, observando-as, ouvindo-as, 
dialogando com elas, que o presente estudo tomou forma. Pinto e Sarmento (apud MÜLLER, 2006, p. 1) salientam:

O olhar das crianças permite revelar fenômenos sociais que o olhar dos adultos deixa na penumbra ou obscurece totalmente. Assim, interpretar as representações sociais das crianças pode ser não apenas um meio de acesso à infância como categoria social, mas às próprias estruturas e dinâmicas sociais que são desocultadas no discurso das crianças.

Assim, o presente estudo teve como corpus de análise os dados produzidos mediante a participação das crianças - inseridas no contexto da cultura de pares -, objetivando investigar quais representações de feminino e masculino elas vêm construindo e utilizando.

No que se refere a pesquisas relacionadas aos estudos de gênero, há de se considerar um número bastante significativo. Alguns destes estudos nos mostram que, ao longo da história, adultos e crianças reforçam algumas ideias binárias em relação aos modos de ser homem/menino, mulher/menina. Porém são poucos aqueles que tensionaram ${ }^{4}$ tais questões com as próprias crianças.

O caminho escolhido para realizar esta pesquisa - dialogar com as crianças sobre gênero - foi pensado a partir de nossas experiências de interação com as crianças no cotidiano escolar. Nas diferentes situações do dia a dia na escola, deparamo-nos muitas vezes com as próprias crianças delimitando espaços e brincadeiras de acordo com o gênero de cada um, construindo entre elas barreiras que separavam meninas e meninos, gerando desconforto para ambos os gêneros quando um de seus pares transgrediam as regras por elas próprias estabelecidas. Além disto, muitas educadoras acabam reforçando atitudes culturalmente construídas que distinguem as crianças de acordo com o sexo que nasceram.

Com isso, atentar para o que as crianças pensam, dialogam com seus pares e representam sobre ser menino e ser menina é de extrema importância, sendo uma dentre tantas outras possibilidades de dialogar/pesquisar com as crianças.

\section{Escola - Família - Gênero - Mídia - Criança. O que há nesta relação?}

A imersão no contexto da Educação Infantil como professora e pesquisadoras permitiu-nos observar o quanto os infantis manifestam suas representações de gênero nos diferentes momentos de interação no ambiente escolar. Desde o brincar livre na sala até as brincadeiras de pátio, evidencia-se uma nítida demarcação entre meninas e meninos. Além disso, há certa "proibição" - estabelecida por parte das próprias crianças e também da escola, por meio da separação dos brinquedos - de acesso a determinados brinquedos expostos na sala ou no pátio, havendo uma limitação estabelecida também pelas crianças, de brinquedos e espaços próprios para cada um dos sexos.

Estas diferenças manifestadas pelas crianças na escola são o resultado do que a cultura em que a criança está inserida acaba por transmitir-lhe desde a mais tenra idade. Inúmeras agências reguladoras de

\footnotetext{
${ }^{4}$ Ao longo deste artigo optamos por empregar o verbo tensionar no sentido de colocar sob tensão determinados temas com as crianças. Consideramos que ele expressa de forma bastante pertinente as operações de pensamento que gostaríamos de desencadear junto às crianças em relação ao assunto pesquisado. A nosso ver, tendo em vista a faixa etária, ele é mais adequado do que, por exemplo, problematizar ou discutir.
} 
condutas - escolas, igrejas, cinemas, a própria familia - ditam às crianças maneiras de ser e estar de acordo com certos parâmetros criados em sociedade. Para Felipe (2000, p. 169), "há um enorme investimento da sociedade em geral para que os sujeitos sejam ou se comportem dessa ou daquela forma, que gostem de determinadas coisas em função do seu sexo". Segundo Finco (2013, p. 6), "as relações de gênero e poder nos processos de socialização de crianças são repletas de estratégias voltadas à normalização e ao controle das expressões corporais". De acordo com a autora, há um estranhamento, por parte dos adultos, quando as meninas passam a maior parte do tempo junto aos meninos e gostam de jogar futebol e quando os meninos, por sua vez, apreciam fantasiar-se ou preferem brincar com meninas, passando a ser questionados e observados como se tivessem alguma anormalidade (FINCO, 2013). A família acaba por inserir a criança nos conceitos compartilhados sobre gênero, como que a preparando para dar as respostas que a sociedade espera sobre seu comportamento, investindo em certos posicionamentos "para tornar o gênero inteligível e normalizado a fim de garantir que sua filha ou seu filho obtenha o gênero correto" (BRITZMAN, 1996, p. 77, grifos da autora).

Segundo Declercq e Moreau (2013), desde os primeiros dias de gestação, os pais dos bebês tratam de diferenciar o ambiente da casa, escolhem roupas e brinquedos em relação ao que é para menino e o que é para menina. As brincadeiras entre pais e filhos também são diferenciadas de acordo com o sexo da criança, "quando brincam com os bebês, os pais [...] são mais propensos a incentivar os meninos a fazer movimentos motores amplos, tais como saltar e abanar os braços, ao passo que as meninas são incentivadas a ser elegantes e delicadas" (RUBLE e MARTIN; SIMITH e LLOYD; apud PAECHTER, 2013, p. 13). Além disso, eles - os meninos - "têm mais chances de ser submetidos a brincadeiras brutas do que as meninas, que, em vez disso, são expostas a mais conversas sobre emoções do que os meninos" (PAECHTER, 2013, p. 13). Ideias naturalistas ainda são difundidas até hoje na sociedade, segundo as quais as mulheres/meninas são vistas como mais sensíveis e os homens/meninos são vistos como mais agressivos (FELIPE, 2000).

Para Brougère (apud KISHIMOTO; ONO, 2008, p. 210), as crianças manifestam as suas experiências vivenciadas, em grande parte, no âmbito familiar e escolar. Conforme argumenta o autor

[...] os estereótipos provêm dos pais e das pessoas que cercam a criança. Os pais constroem o primeiro ambiente de brinquedos da criança, antes que ela comece a fazer suas escolhas. No nascimento, o quarto das meninas é rosa, com bonecas, e o dos meninos é azul, com carros em miniatura. As meninas costumam brincar de "casinha" e representam o papel da mãe; os meninos, de "motorista", que dirige o carro. É o contexto em que a criança vive, especialmente o meio familiar, que dirige inicialmente tais escolhas.

Mas não só a família, como também a escola, acabam por reproduzir ideias socialmente construídas sobre as questões de gênero. No que se se refere à escola, alguns estudiosos chamam a atenção para o quanto o ambiente escolar tem sido colaborador para a construção das identidades dos aprendizes. Segundo Britzman (1996, p.72) 
a escolarização produz não apenas formas de conhecimento e relações particulares de desigualdade, ao longo de divisores de raça e gênero, mas, mais imediatamente, produz e organiza, de forma coincidente, as identidades raciais, culturais e generificadas dos/as estudantes.

Esta autora argumenta que na escola "são oferecidas e policiadas" representações de identidades. A escola acaba por operar normas e regras de comportamento entendidas socialmente como apropriadas para cada um dos gêneros. Guizzo (2005, p.66) também fala sobre uma "regulação da cultura sobre os meninos". Em sua pesquisa, a autora observou que tanto meninas quanto meninos sofrem regulações e controles empreendidos na escola, embora tenha constatado que nas situações que envolviam os meninos, os atos regulatórios eram muito mais constantes (GUIZZO, 2005).

Assim como a escola e a família, a mídia em geral - jornais, revistas, publicidades, propagandas de rádio e em especial a televisão - também ensinam modos de ser menino e de ser menina, fazendo circular conceitos não só de gênero, mas também de raça, etnia e sexualidade, por exemplo. Sobre o último artefato - a televisão - as crianças, na maioria das vezes, possuem livre acesso a ele em suas residências, sendo convocadas por inúmeros enunciados que também vão colaborar para a construção de representações sobre identidades de gênero e contribuir na constituição de suas subjetividades. Rosa Fischer (apud FELIPE e GUIZZO, 2003, p. 121) aponta a televisão e a mídia, de modo mais específico, como "um lugar privilegiado de aprendizagens diversas; aprendemos com ela desde formas de olhar e tratar nosso próprio corpo até modos de estabelecer e de compreender diferenças de gênero". Tais diferenças são muitas vezes interpretadas pelas crianças e reproduzidas por elas próprias na sociedade. Com isto, as crianças vêm sendo expostas a inúmeras informações e regulamentações, que acabam ensinando a elas formas de ser menina e menino.

\section{Cultura de pares - tensionando, negociando, aprendendo e confrontando significados}

Estudos nos mostram que as crianças interpretam significados do mundo adulto e por elas próprias reproduzem tais significados de maneira subjetiva em colaboração com seus pares. Tais estudos são decorrentes de pesquisas que objetivam observar a relação social das crianças. Dentre estas pesquisas, os trabalhos de Willian Corsaro $(1985,1992,2011)$ vêm ganhando destaque no âmbito da Sociologia da Infância em especial. O pesquisador acredita que as crianças pequenas são capazes de manter uma interação contínua entre elas e que seu desenvolvimento social é influenciado por interações com seus pares (CORSARO apud MÜLLER, 2007). Para o autor, cultura de pares é definida como "um conjunto estável de atividades ou rotinas, artefatos, valores e preocupações que as crianças produzem e compartilham na interação com seus pares" (CORSARO, 2011, p. 13). Corsaro aponta para as observações que realizou nas quais pode concluir que as crianças apropriam-se das informações do mundo 
adulto e também do ambiente escolar ao qual pertencem, essas informações são utilizadas por elas para produzirem novas rotinas que elas mesmas criam e ampliam de maneira coletiva em suas culturas de pares (CORSARO, 2011). Ou seja, as crianças quando inseridas com seus pares tendem a negociar, discutir e (re)formular conceitos e hipóteses que foram por elas aprendidas através do mundo adulto em que vivem. Para o pesquisador, as crianças "não apenas imitam ou reproduzem aspectos do mundo adulto, mas também os confrontam, manipulam e transformam" (CORSARO, 2011, p.15).

Com o conceito de "reprodução interpretativa", o autor reafirma a ideia de que as crianças e suas infâncias são afetadas pelas sociedades e culturas das quais fazem parte. Neste sentido, o termo "reprodução" significa que "as crianças não apenas internalizam a cultura, mas contribuem de maneira ativa para a produção e mudança cultural" (CORSARO, 2009, p. 31). Já o termo “interpretativa”, segundo o autor:

[...] captura os aspectos inovadores da participação das crianças na sociedade, indicando o fato de que as crianças criam e participam de suas culturas de pares singulares por meio da apropriação de informações do mundo adulto de forma a atender aos seus próprios interesses enquanto crianças (CORSARO, 2009, p. 31).

Com isto, ao analisar as interações das crianças que participaram da pesquisa, constatamos que a todo o momento as crianças discutiam entre elas sobre aquilo que estava sendo problematizado, neste caso, sobre gênero. Portanto, embora, muitas vezes, apresentem em suas falas visões provenientes do mundo adulto, ao mesmo tempo, elas (re)elaboram-nas após confrontá-las e negociá-las com seus pares. As crianças, de certo modo, buscam informações das culturas escolares e do mundo adulto para recriá-las e expandir em suas próprias culturas, construindo, por meio disto, sua identidade enquanto sujeito em interação com outros.

Durante os diálogos propostos para esta pesquisa, foi possível observar momentos de trocas entre as crianças. Em alguns, elas emitiam suas opiniões, gerando, de certo modo, um confronto de ideias - o que, às vezes, ocasionava mudanças de um determinado ponto de vista entre elas, sendo possível perceber, por meio de suas falas, que as mesmas se apropriam das experiências que vivenciam, seja na família e/ou na escola, para manifestar interesses e desejos enquanto sujeitos inseridos em uma sociedade. As crianças defendiam seus pontos de vista, confrontando-os e negociando-os com seus pares; por vezes, acabavam por assumir outros posicionamentos sobre determinadas ideias.

Ferreira (2002, p.167) também aborda esse processo entre as crianças, afirmando que

[...] o sentido da acção não se refere às intenções e razões expressas isoladamente pelos sujeitos, mas é intrínseco ao carácter imputável da reflexividade da interacção, onde a mobilização das reservas de conhecimento de que cada criança individualmente dispõe as leva ao seu confronto com as de outros e as que encontram à sua disposição no próprio decorrer da produção e reprodução da ação.

Ainda de acordo com Ferreira (2002, p. 167), os infantis

[...] decorrentes da adopção, do confronto e contraponto perante a ordem adulta ou entre pares, emergem regras e princípios de acção no interior do grupo que são usados como conhecimentos e competências sociais para participarem no mundo adulto e ao mesmo tempo para se afirmarem perante ele. 
Deste modo, podemos afirmar que as crianças buscam informações das vivências no mundo adulto, assim como incorporam formas de compreender o mundo que as cerca; ao mesmo tempo, porém, elaboram com seus pares significados próprios que irão contribuir para que se constituam como sujeitos produtores de sua própria cultura. E mesmo que, de alguma maneira, as crianças reproduzam posturas e visões dos adultos, elas próprias apresentam modos subjetivos de se apropriarem dos conceitos socialmente construídos sobre gênero. Buss-Simão (2012) apresenta uma importante contribuição no que se refere a estes posicionamentos, ajudando-nos a compreender como as crianças esboçam certas posições sobre gênero e, ao interagirem com seus pares ou com os adultos, os modificam. Segundo Buss-Simão (2012, p.199),

[...] as negociações de um posicionamento das noções de gênero envolvem o entendimento de que, embora as crianças se considerem irrevogavelmente membros de um determinado grupo de gênero, elas ainda não têm certeza sobre quais tipos de comportamentos são apropriados para membros desse grupo.

Conforme os apontamentos de Buss-Simão (2012, p. 199), o conceito de posicionamento torna-se relevante para entendermos que os possíveis modos "das crianças construírem e assumirem o gênero não decorre de uma inerência biológica concreta, nem de uma inerência social abstrata, mas sim, porque se confrontam e jogam em ações situadas, as quais são múltiplas, complexas, contraditórias e dinâmicas”. E prossegue

Por serem dicotômicas e contraditórias, algumas vezes, as crianças se tornam resistentes e desafiam a imposição de estereótipos, noutras vezes, atualizam, reproduzem e acentuam esses mesmos estereótipos. Até porque, esses posicionamentos são inseparáveis das diferentes posições relativas de poder e dominância que as crianças, entre pares, ocupam nas relações sociais em que se cruzam categorias como gênero, idade, classe social, etnia, etc (BUSS-SIMÃO, 2012, 199).

Por fim, em nossa pesquisa, foi possível observar que as crianças assumiam/trocavam/abandonavam, mesmo que provisoriamente, diferentes posicionamentos a partir dos diálogos e negociações entre seus pares. 


\section{Caminhos metodológicos - dialogando com crianças.}

A pesquisa foi realizada com um grupo de crianças de 4 a 5 anos, em uma turma de Maternal II, denominada como Maternal II B, de uma escola de Educação Infantil da rede municipal de Canoas, região metropolitana de Porto Alegre. A turma era constituída por 20 crianças das quais 18 participaram da pesquisa.

Para instigar o diálogo com as crianças, objetivando compreender quais suas representações sobre feminino e masculino, foram pensados e organizados seis encontros. Diferentes recursos foram utilizados para cada uma das sessões, com o intuito de despertar o interesse dos sujeitos para as discussões: brinquedos diversos, imagens de revistas, imagens de obras de arte e contação de histórias. Também foi explorada uma atividade de recorte e colagem de imagens que haviam sido objeto de discussão em momento anterior.

Para o primeiro encontro foram organizadas duas caixas de brinquedos, tradicionalmente definidos como "para meninas" e "para meninos". As caixas serviram de convite para iniciar as discussões com o grupo. No segundo encontro, foram utilizadas imagens de revistas e da internet que suscitavam leituras mais abertas sobre os modos de ser homem e ser mulher, de ser menino e de ser menina; dez imagens foram selecionadas como ponto de partida para os debates. Já no terceiro encontro, foram expostas ao grupo dez imagens de obras de arte, previamente selecionadas, dentre as quais incluíam-se obras dos artistas Joan Miró, Pablo Picasso e Albrecht Dürer. Tais imagens foram escolhidas porque em muito se distanciam da gama cultural que compõe o entorno social destas crianças, uma vez que elas e suas famílias não frequentam museus e galerias de arte.

Para o quarto encontro, denominado "Dia do avesso", as crianças foram convidadas a explorar roupas, fantasias e acessórios, como bonés, bolsas, maletas, óculos, chapéus, para meninas e meninos. Para o penúltimo encontro, intitulado "Com que roupa eu vou?", foram oferecidas novamente às crianças diferentes imagens de revistas mostrando mulheres, homens e crianças, vestidos de diversas formas (mulheres com calças, camisas, shorts, tops, vestidos longos, vestidos curtos, saias, blusas; homens com camisas sociais, terno e gravata, camisetas e shorts esportivos, de pijamas, de kilt; crianças com roupas mais esportivas, outras mais sociais, outras despojadas). As crianças deveriam escolher uma roupa e um calçado que gostassem para irem a uma festa. Depois deveriam recortá-los e colar os modelos escolhidos em um painel.

No último encontro, foi narrada a história "Jeitos de ser", da autora Nye Ribeiro (2000), e se instigava as crianças a pensarem da seguinte forma: se pudessem ser outra coisa e não o que eram, como gostariam de ser? A história apresentava a possibilidade de ser outra coisa, a partir de elementos da natureza, como um pássaro, uma árvore, um rio, entre outros. Por fim, o livro fazia o seguinte questionamento: "Então, que tipo de gente gostaria de ser?" Após este questionamento, foram apresentadas às crianças imagens de diferentes pessoas -crianças, mulheres e homens de diferentes idades, 
de diferentes biótipos e raças - seguidas da seguinte pergunta: "Se você fosse outra pessoa, qual pessoa gostaria de ser?"

As sessões tiveram como objetivo observar e compreender como as crianças faziam suas escolhas perante brinquedos culturalmente definidos como para meninos e para meninas, como se organizavam para brincar e o que pensavam sobre estes artefatos culturais; quais suas opiniões sobre as formas expostas na cultura de ser homem/menino, mulher/menina; quais suas representações no que se referia às figuras feminina e masculina frente às obras de arte; quais significados eram atribuídos pelas crianças ao comportarem-se como menina e/ou menino; o que pensavam em relação às vestimentas para mulheres/meninas, homens/meninos, ou seja, o que consideravam adequado ou não para cada um/a; quais características físicas valorizavam, na medida em que mostravam desejo de vir a ser de tal modo, e ainda, quais eram suas representações de belo e feio.

O conjunto de imagens selecionadas para este trabalho foi um importante artefato que colaborou para fomentar as discussões e tensionar as opiniões em vários momentos. Um roteiro de perguntas foi também construído para cada sessão para que fosse possível iniciar os debates. Além disso, embora houvesse um roteiro previsto e antecipadamente pensado em termos de perguntas e proposições a serem feitas às crianças com base nos materiais e propostas de cada sessão, buscou-se prestar atenção às suas respostas e, sobretudo, àquilo que poderia mobilizar e dinamizar as manifestações e conversas.

As narrativas das crianças foram gravadas, para que, posteriormente, fosse possível perceber e compreender as posições das crianças frente às situações apresentadas. Em cada um dos encontros foram utilizados diversos recursos, sendo que todos eles oportunizaram tensionar, de diferentes formas, o ponto de vista das crianças. Além das gravações, também foi utilizado um caderno de anotações para breves relatos dos momentos destinados apenas à observação das interações das crianças.

A partir dos tensionamentos propostos às crianças durante a pesquisa, já aqui brevemente relatados, foi possível observar nas falas das crianças nos encontros as regulações acerca do que é ser menina e menino. Elas expressaram visões adultocêntricas sobre aspectos relacionados aos marcadores de gênero, como por exemplo, os estilos das roupas e suas cores - sendo o rosa uma cor unicamente destinada às meninas; o estilo do cabelo - curto para os homens/meninos e compridos para as mulheres/meninas; os brinquedos e brincadeiras "cabíveis" para um e para outro. Assim como regulavam as ações de meninos e meninas como sendo corretas para cada um dos sexos, colaborando para a construção de fronteiras entre ambos.

Estas posturas foram explícitas durante os momentos de brincadeira livre, em que as meninas se dedicam a brincar somente com brinquedos relacionados aos afazeres domésticos, enquanto os meninos travavam batalhas com "homenzinhos" ou jogavam futebol, reforçando a ideia de força e agilidade que a sociedade lhes impõe. Paechter (2013, p. 14) argumenta que "as crianças pequenas são muito conscientes do que os pais fazem em casa e estabelecem generalizações a partir disso". Segundo o autor, "as crianças sentem que sua identidade de gênero é ameaçada por comportamentos não estereotipados" (PAECHTER, 
2013, p. 15). Conforme as falas das crianças, é possível perceber que as formas estereotipadas são para elas uma afirmação de modos corretos de feminilidade e masculinidade.

No que se refere à exploração dos brinquedos a que tiveram acesso no momento da pesquisa, há uma regulamentação pelas próprias crianças, como se proibissem a si próprias de explorar os brinquedos que culturalmente são classificados como destinados aos sujeitos do sexo oposto ao seu. Após a mediação, algumas crianças aceitaram manipular e brincar com determinados tipos de brinquedos, outras crianças ainda continuavam demonstrando recusa.

Outras questões também surgiram nas falas das crianças, sendo importante destacá-las. A primeira se refere ao consumo da beleza. Gavião (2013) ressalta em sua pesquisa como a beleza é primordial para as crianças, sobretudo para as meninas. Para elas, ser bela é inscrever-se no arranjo social, sendo importante para qualquer sujeito, independentemente do sexo (GAVIÃO, 2013). Os achados de Gavião (2013) ajudam a compreender o que relataram as crianças que fizeram parte de nossa pesquisa: através de alguns tensionamentos, elas manifestaram certo desejo de consumir a beleza do outro. Algumas expressaram o desejo de possuir um corpo bonito. Para as meninas, as características que se referiam à beleza eram jovialidade, exuberância, nobreza, sensualidade e a raça branca, representando tais aspectos por meio de imagens de mulheres jovens, magras, ricas, brancas, com cabelos longos e lisos. Outro fator que influenciou fortemente na escolha das meninas foram as vestimentas que apareciam nas imagens todas as imagens que elas mostraram estavam com roupas em que a maior parte do corpo feminino estava à mostra, como por exemplo, mini-saias, mini-shorts, vestidos curtos e muito justos, bem como decotes. Já para os meninos, tais características relacionavam-se à jovialidade, à nobreza e à força. Os modelos de beleza aspirados por meninas e meninos correspondem a padrões que a cultura e, de modo mais contundente, a mídia, têm difundido como desejáveis nas últimas décadas.

Com isto, podemos observar que desde bem pequenas as crianças passam a operar a partir daquilo que estão acostumadas a vivenciar, seja pela erotização exposta na mídia, ou pelas experiências próximas em que estão imersas. Esta erotização é problematizada pelas autoras Felipe e Guizzo (2003, p.128). Para elas,

As representações sobre sexualidade, corpo e gênero, veiculadas em especial pela mídia, têm subjetivado não só adultos, homens e mulheres, mas também têm trabalhado minuciosamente para a formação das identidades infantis e juvenis nos nossos dias. Os corpos vêm sendo instigados a uma crescente erotização, amplamente veiculada através da TV, do cinema, da música, em jornais, revistas, propagandas, outdoors, e, mais recentemente, com o uso da internet.

A imagem da mulher brasileira veiculada pela mídia tem sido representada por uma acentuada sexualidade; de modo especial, o erotismo e a sexualidade têm sido postos como centrais à existência dos sujeitos (FELIPE, 2000). Da mesma forma como na mídia os corpos que não se ajustam a tais características estereotipadas não são bem vistos, as crianças também demonstraram certo desagrado pelas imagens das pessoas com mais idade, obesas e negras. Gaudio (2013) destaca em seus estudos o quanto a 
erotização, estimulada demasiadamente pelas mídias, tem contribuído para a formação das crianças. Conforme a autora,

[...] os corpos são estimulados a uma erotização divulgada excessivamente pelas mídias, explorando corpos e sexualidades. Essa erotização atinge cada vez mais a vida das crianças, sobretudo em relação às meninas, que desde cedo estão sujeitas aos discursos naturalizados considerados "verdades universais" a respeito dos padrões corporais (GAUDIO, 2013, p. 195).

Na pesquisa que desenvolveu, Gaudio (2013) discorre sobre as relações entre as crianças que observou e chama a atenção, em especial, para o grupo das meninas. Segundo a autora, as meninas "pareciam conhecer muito bem as características consideradas sinônimo de belo e saudável, assim como desejavam os produtos de embelezamento" (GAUDIO 2013, p. 195). A autora aponta que, em muitos momentos, as crianças observadas em sua pesquisa traziam para a escola vários objetos de maquiagens, como batom, sombras, blush, entre outros. Tais objetos, ao mesmo tempo em que geravam posicionamentos de gênero, também fomentavam conflitos entre as crianças (GAUDIO, 2013, p. 195196).

Tendo discorrido sobre algumas das questões que emergiram nos diferentes momentos de diálogos com as crianças, cabe ainda atentar para as inúmeras possibilidades de se pesquisar com crianças, pois como se pode observar através do estudo aqui exposto, muitos são os assuntos e interesses que surgem no diálogo com as crianças e entre elas que merecem a atenção e o cuidado de pesquisadores e também de professores enquanto pesquisadores. O estudo realizado por Gaudio (2013) mostra a necessidade de se estar atento ao que emerge durante a pesquisa de campo. A pesquisadora, na busca de compreender os processos sociais das crianças com seus pares e com os adultos quanto às diferenças étnico-raciais, identificou dois aspectos envolvidos nessa relação, quais sejam: a dimensão corporal e as relações de gênero (GAUDIO, 2013).

Os resultados apresentados por Gaudio (2013) assemelham-se com os achados do trabalho aqui apresentado. Para Gaudio (2013, p.11),

Uma característica marcante observada entre as crianças foi que nas diferentes formas de organização social, elas exprimiam seus modos de ver e interpretar o mundo através de aspectos que envolviam o corpo, sendo possível perceber, nas relações entre pares, a recorrência de elementos particulares que diferenciavam e hierarquizavam suas relações, sobretudo no que diz respeito aos elementos étnico-raciais, de gênero e a aparência física.

Ambas as pesquisas contribuem para futuros estudos que objetivem investigar as relações sociais das crianças e suas formas de compreender o mundo, tendo as próprias crianças como sujeitos ativos na cultura da qual fazem parte. 


\section{Considerações finais}

As pesquisas com crianças vêm ganhando visibilidade no campo educacional, mas ainda são poucos os estudos acadêmicos que permitem que os infantis assumam este lugar ativo nas investigações sobre temas que abordam a infância.

Contudo, é imprescindível que mais pesquisas sejam realizadas com as crianças, para que possam ser ouvidas e compreendidas a partir do que pensam e do que é de seu interesse, colocando-as como sujeitos da pesquisa, privilegiando suas falas, sentimentos, hipóteses e representações acerca do mundo do qual fazem parte.

Embora as crianças apresentem em suas representações as falas dos adultos, ou seja, demonstrem uma visão adultocêntrica, estas representações que constituem as subjetividades de cada criança podem ser negociadas em sua cultura de pares. Conforme Louro (apud FELIPE, 2000, p. 175, grifos da autora), "as representações não são, contudo, meras descrições que 'refletem’ as práticas desses sujeitos; elas são, de fato, descrições que os 'constituem, que os 'produzem' [...]" e deste modo, merecem ser ouvidos com destaque.

É importante destacar que, embora os caminhos metodológicos percorridos nesta pesquisa direcionassem, em parte, as discussões durante os encontros, como resultado, os dados coletados acabaram por formar um leque para tantas outras possibilidades de análise. Ou seja, as discussões que inicialmente tratavam dos aspectos relacionados a gênero acabaram problematizando outros temas que mereceriam reflexão devido a sua relevância para a educação, podendo sugerir questões para novos estudos. 


\section{Referências}

BRITZMAN, Deborah P. O que é essa coisa chamada amor: identidade homossexual, educação e currículo. Educação \& Realidade. Porto Alegre. jan./jun. 1996, v.21, 71-96.

BUSS-SIMÃO, Márcia. Relações sociais em um contexto de educação infantil: um olhar sobre a dimensão corporal na perspectiva de crianças pequenas. 2012. 312 f. Tese (Doutorado em Educação) Universidade Federal de Santa Catarina, Florianópolis, 2012. Disponível em: <http://repositorio.ufsc.br/xmlui/handle/123456789/96146>. Acesso em: 15 ago. 2016.

CORSARO, William Arnold. Reprodução interpretativa e cultura de pares. In: MÜLLER, Fernanda e CARVALHO, Ana Maria Almeida Carvalho (Orgs.). Teoria e prática na pesquisa com crianças: diálogos com William Corsaro. São Paulo: Cortez Editora. 2009. p. 31-50.

Faz de conta, aprendizagem e infância viva. Revista Pátio: educação infantil. Porto Alegre. abr./jun. 2011, ano IX, n.27, 12- 15.

Friendship and peer culture in the early years. Norwood: Ablex, 1985.

Sociologia da infância. Tradução: Lia Gabriele Regius Reis. Porto Alegre: Artmed, 2011.

CORSARO, W. A., \& MILLER, P. J. Interpretive approaches to children's socialization. San Francisco: Jossey Bass, 1992.

DECLERCQ, Christelle; MOREAU, Daniéle. As crianças não nascem meninos ou meninas: tornam-se um ou outro. Revista Pátio: educação infantil. Porto Alegre. jul./set. 2013, ano XI, n.36, 19- 21.

FELIPE, Jane. Entre tias e tiazinhas: pedagogias culturais em circulação. In: SILVA, Luiz Heron (Org.) Século XXI: qual o conhecimento? Qual currículo? 2.ed. Petrópolis: Vozes, 2000. p. 167-179.

FELIPE, Jane; GUIZZO, Bianca Salazar. Erotização dos corpos infantis na sociedade de consumo. Proposições. Campinas. set./dez. 2003, v.14. n.3, 119-130. Disponível em: http://www.proposicoes.fe.unicamp.br/proposicoes/textos/42-dossie-felipej etal.pdf

FERREIRA, Maria Manuela Martinho. “- A gente aqui o que gosta mais é de brincar com os outros meninos!” - as crianças como atores sociais e a (re) organização social do grupo de pares no cotidiano de um Jardim de Infância. 2002. 722f. Dissertação (Doutoramento em Ciências da Educação) - Universidade do Porto, Faculdade de Psicologia e Ciências da Educação, Porto, 2002. Disponível em: <http://hdl.handle.net/10216/19509>. Acesso em: 15 ago. 2016.

FINCO, Daniela. Os perigos da naturalização das relações sociais na educação infantil. Revista Pátio: educação infantil. Porto Alegre. jul./set. 2013, ano XI, n.36, 05-07.

GAUDIO, Eduarda Souza. Relações sociais na educação infantil: dimensões étnico-raciais, corporais e de gênero. 2013. 242f. Dissertação (Mestrado em Educação) - Universidade Federal de Santa Catarina, Florianópolis, 2013. Disponível em <https://repositorio.ufsc.br/handle/123456789/107136>. Acesso em: 15 ago 2016.

GAVIÃO, Juliane Falcão. Representações de gênero e consumo na pesquisa com crianças. 2013. 176f. Dissertação (Mestrado em Educação) - Universidade Luterana do Brasil, Canoas, 2013. Disponível em: <https://memphis.ulbranet.com.br/BIBLIO/PPGEDUM145.pdf>. Acesso em: 20 jan. 2013. 
GOBBI, Márcia. Desenho infantil e oralidade: instrumento para pesquisa com crianças pequenas. In: FARIA, A. L. G. e DERMATINI, Z. de B. F.; PRADO, P. D. (Orgs.). Por uma cultura da infância: metodologias de pesquisa com crianças. Campinas: Autores Associados, 2002. p. 69-92.

GUIZZO, Bianca Salazar. Identidades de gênero e propaganda televisivas: um estudo no contexto da Educação Infantil. 2005. 145f. Dissertação (Mestrado em Educação) - Universidade Federal do Rio Grande do Sul, Porto Alegre, 2005.

KISHIMOTO, Tizuko M.; ONO, Andréia Tiemi. Brinquedo, gênero e educação na brinquedoteca. Proposições. Campinas. set./dez. 2008, v.19, n.3 (57), 209-223. Disponível em: http://www.scielo.br/scielo.php?script=sci arttext\&pid=S0103-73072008000300011

MÜLLER, Fernanda. Entrevista com William Corsaro: entrevista. Educação e sociedade. Campinas. jan./abr. 2007, v.28, n.98. Disponível em: http://www.scielo.br/scielo.php?pid=S0101$\underline{73302007000100014 \& \text { script }=\text { sci arttext }}$

Infância nas vozes das crianças: culturas infantis, trabalho e resistência. Educação e Sociedade.
Campinas.
mai./ago.
2006 ,
v.27,
n.95.
Disponível
em:

http:/ / www.scielo.br/scielo.php?script=sci_arttext\&pid=S0101-73302006000200012\&Ing=pt\&nrm=iso

PAECHTER, Carrier. Por que meninos e meninas escolhem brinquedos diferentes. Revista Pátio: educação infantil. Porto Alegre. jul./set. 2013, ano XI, n.36, 13-15.

RIBEIRO, Nye. Jeitos de ser. 2.ed. São Paulo: Editora do Brasil, 2000. 